\title{
Solar Based Stand Alone High Performance Interleaved Boost Converter with Zvs and Zes
}

\author{
Ms.Nicy v.b ${ }^{1}$, Mr.V.Karthikeyan ${ }^{2}$ \\ ${ }^{I}(P G$ Scholar (EEE),Hindusthan college of Engineering and Technology, Coimbatore) \\ ${ }_{2}^{2}$ (Asst.professor(EEE),Hindusthan College of Engineering and Technology, Coimbatore)
}

\begin{abstract}
This paper introduces interleaved boost converters topology for PFC (power-factor-corrected), which has continuous input current that you can manipulate with average-current-mode-control techniques to force input current to track changes in line voltage. The concept of interleaving, or more generally that of increasing the effective pulse frequency of any periodic power source by synchronizing several smaller sources and operating them with relative phase shifts. With the help of the interleaving technology the inductor current of interleaved boost converter can be reduced and thus inductor size is reduced. The Zero voltage technique provides perfect turn on process of the converter. There is no overlap between the voltages and current, hence no switching loss takes place at turn on process. The performance of proposed work is tested and verified by MATLAB/SIMULINK software.
\end{abstract}

Keywords - interleaved boost converter, power factor correction (PFC), switching loss, zero-current switching (ZCS), zero-voltage switching (ZVS).

\section{INTRODUCTION}

The power factor is defined as the ratio of the average power to the apparent power at an AC terminal. When a converter has less than unity power factor means that the converter absorbs apparent power higher than the real power consumes. This implies that the power source should be rated with higher VA ratings than the load needs. In addition the current harmonics converter produces deteriorate the power source quality, which affect the other equipment. The solution to improve the power factor is to add a passive filter, which is composed of a capacitor and an inductor. However this passive filter is inefficient and bulky since it operates at the line frequency. Therefore, thepower factor correction stage has to be inserted to the existing equipment to achieve a good power factor. The PFC technique reduces current harmonics in utility systems produced by nonlinear Load. Interleaved operation (the parallel connection of switching converters) of two or more boost converters has been proposed to increase the output power and reduce the output ripple current [1]-[7]. This technique consists of a phase shifting of the control signals of several cells in parallel operating at the same switching frequency. As a result, the input and output current waveforms exhibit lower ripple amplitude. Highswitching-frequency operation is necessary to achieve small size of the converter. However, the switching loss will increase as the switching frequency is increased. To solve these problem, soft switching techniques are necessary. The zero-voltage-switched (ZVS) technique and zero-current-switched (ZCS) technique are two commonly used soft switching methods. By adopting these ZCS and ZVS techniques, either voltage or current is zero during switching transitions, which reduces the switching loss and also increases the reliability of the power supplies. The choice of the soft-switching technique, i.e., ZCS(zero current source) or ZVS, it is taking into account them technology of the semiconductor device will be used. For example, Power MOSFETSs present a better performance when these are commutated under ZVS since they exhibit turn-on capacitive losses when operating in ZCS increasing the switching losses and EMI. On the other, the IGBTs present better results when are commutated under ZCS which can avoid their lath up and the turn-off losses caused by the tail current. The ZCS techniques have some drawbacks such as a significant voltage stress on main diode, which increases the conduction losses, and presence of the resonant inductor in series with the main switch, which increases the magnetic losses. The technique of zero voltage switching is applicable to all switching topologies ZVS technique [9]-[11]basically consists of forcing to zero the active switch voltage that prior to its turn-on by creating a resonance between an inductor and a capacitor. The inductor also limits the rate of variation of the diode current so losses due to the reverse recovery are reduced as well converter are simple topology, , fast transient response,high power density and continuous input current. Therefore, the boost converters are usually used in different power electronics applications such as active PFC, photovoltaic power systems and fuel cells. Also interleaved operation (the parallel connection of switching converters) of two or more boost converters has been proposed to increase the output power and to the reduce output ripple. This consists of a phase shifting of the control signals of several cells in parallel operating at the same switching frequency. As a result, the input and output current waveforms exhibit lower ripple amplitude. 
High-switching-frequency operation is necessary to achieve small size of the converter. However, the switching loss will increase as the switching frequency is increased. To solve these problem, soft switching techniques are necessary. The zero-voltage-switched (ZVS) technique and zero-current-switched (ZCS) technique are two commonly used soft switching methods. By adopting in these techniques, either current or voltage is zero during switching transitions, which reduces the switching loss and also increases the reliability of the power supplies. The choice of the soft-switching techniques, i.e., ZCS or ZVS, it is taking into account the technology of the semiconductor device that will be used. For example Power MOSFETSs present a better performance when are commutated under ZVS, since these exhibit turn-on capacitive losses when operating in ZCS increasing the switching losses and EMI. On the other, the IGBTs present better results when are commutated under ZCS which can avoid their lath up and the turn-off losses caused by the tail current. The ZCS techniques have some drawbacks such as, a significant voltage stress on the main diode, which increases the conduction losses, in the presence of the resonant inductor series with the main switch, which increases the magnetic losses. The technique of zero voltage switching is applicable to all switching topologies. ZVS technique basically forcing to zero the active switch voltage that prior to turn-on by creating a resonance between an inductor and a capacitor. The inductor also limits the rate of variation of the diode current so losses due to the reverse recovery are reduced as well.

\section{Interleaved Boost Converter}

Interleaved boost converter composed of two shunted elementary boost conversion units and an auxiliary inductor. Power for the interleaved boost converter can come from any suitable DC sources, such as batteries, solar panels,DC generators and rectifiers. A process that changes one DC voltage to a different DC voltage is called DC to DC conversion. The basic principle of a Boost converter consists of 2 distinct states in the On-state, switch S is closed, resulting in an increase the inductor current; in the Off-state, switch is open and the only path offered to inductor current is through the diode $\mathrm{D}$, the capacitor $\mathrm{C}$ and load R. These results transferring the energy accumulated during the On-state into the capacitor. In the interleaved boost converters cascading two boost converters, so inductor is split in two then huge amount current can be stored.

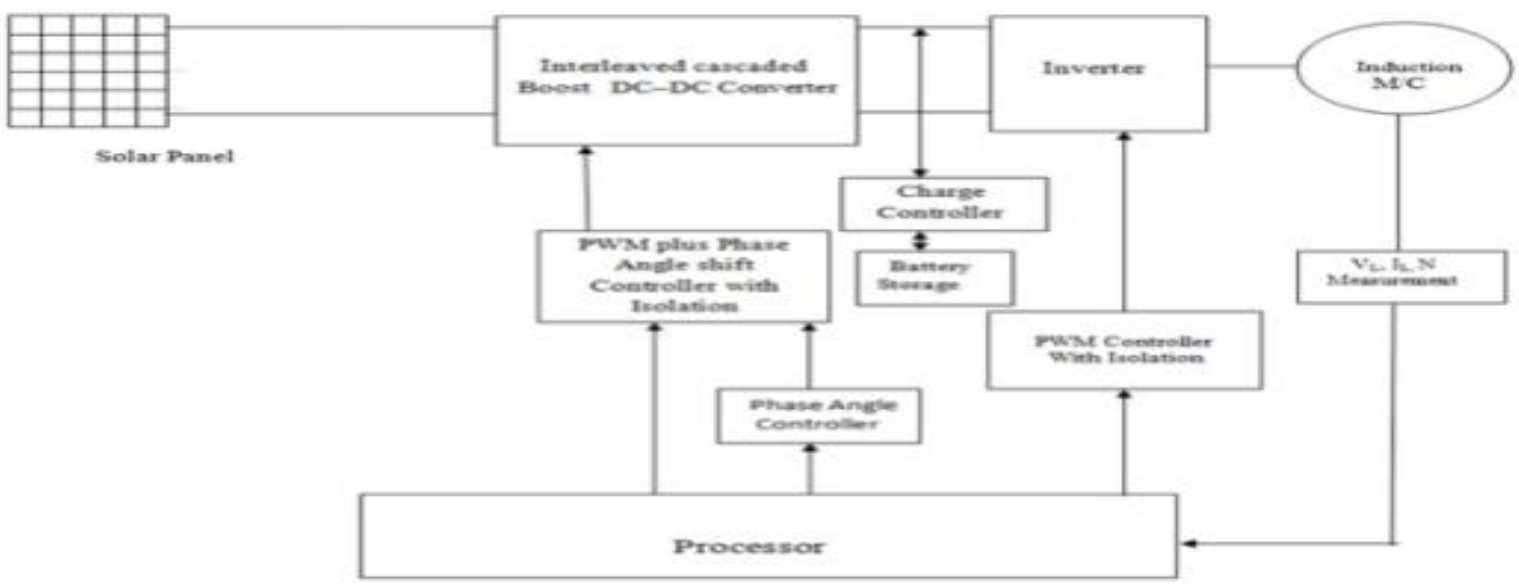

Fig1: Block diagram

So the accuracy of the system can be increased. This converter is able to turn on both the active power switches at zero voltage to reduce their switching losses and raise the conversion efficiency. Since two paralleloperated elementary boost units are identical, operation analysis and design the converter module becomes quite simple. The benefits of interleaving include high power capability, reliability, and improved modularity.

Power for the interleaved boost converter acquired from the solar panel. Solar panels use light energy (photons) from the sun to generate electricity through the photovoltaic effect. Here the operation of two phase interleaved boost converter is explained which is shown in the figure 2. Firstly when the device S1 is turned ON, the current in the inductor iL1 increases linearly. 


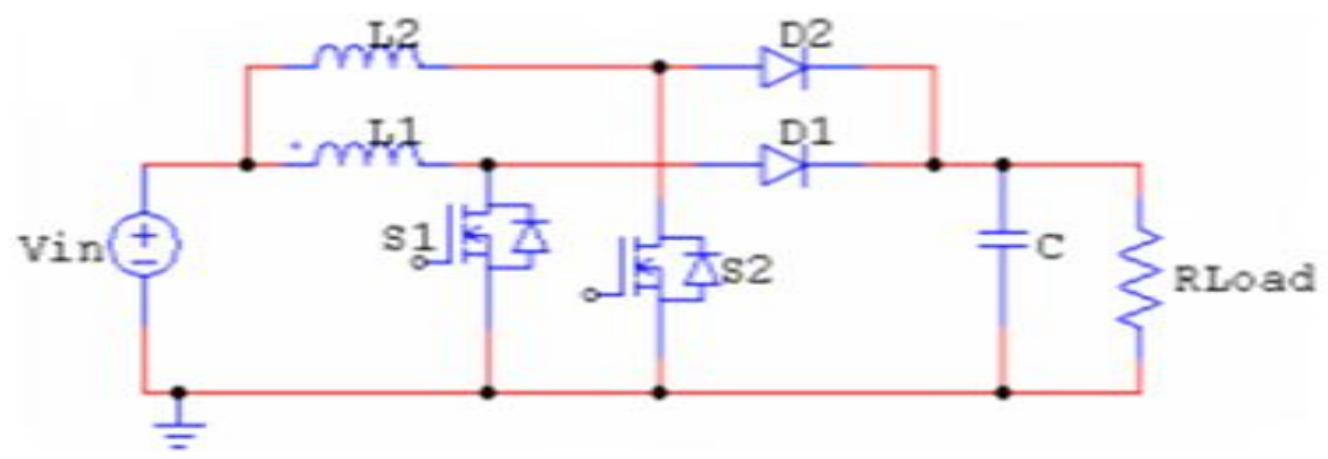

Fig2: Interleaved boost converter

During this period energy is stored in the inductor L1. When S1 is turned OFF, diode D1 conducts and the stored energy in the inductor ramps down with a slope based on the difference between the input and output voltage. The inductor starts to discharge and transfer the current via the diode to the load. After a half switching cycle of S1, S2 is also turned ON completing the same cycle of events. Since both the power channels are combined at the output capacitor and the effective ripple frequency is twice than that of a single-phase boost converter. The amplitude of the input current ripple is small. This advantage makes this topology very attractive for the renewable sources of energy. The gating pulses of the two devices are shifted by a phase difference of $360 / \mathrm{n}$, where $\mathrm{n}$ is the number of parallel boost converters connected in parallel. For a two-phase interleaved boost converter $n=2$, which is 180 degrees. By splitting the current into two power paths, conduction $\left(I^{2} R\right)$ losses can be reduced, and increasing overall efficiency compared to a single-phase converter. Because the two phases are combined at the output capacitor, effective ripple frequency is doubled, that making ripple voltage reduction much easier. Likewise, the power pulses drawn from the input capacitor are staggered, reducing the ripple current requirements. In the figure 1 it can be seen that the input current, i, for two phase interleaved boost converter is the sum of each channels inductors currents. As the two devices are phase shifted by 180 degrees, the input current ripple produced is the smallest.

\subsection{Boost Ratio:}

The boosting ratio of the converter is a function of the duty ratio. It is same as in conventional boost converter. It is defined as

$$
\frac{V_{d c}}{V_{i n}}=\frac{1}{1-D}
$$

Where the output voltage is is the input voltage and $\mathrm{D}$ is the duty ratio.

The result of interleaved boost converter given to the inverter and invert the output which is given to the induction motor. An induction motor, it's a type of AC motor where power is supplied to the rotor by means of electromagnetic induction. The speed of the induction motor is controlled by the frequency of the supply voltage. When driven a fixed line frequency, the motor reduces the speed of rotation. When used in this way, the induction motors are usually run so that in operation the shaft rotation speed is kept above the peak torque point.

ZVS technique basically forcing to zero the a switch voltage prior to its turn-on by creating a resonance between an inductor and a capacitor. The inductor also limits the rate of variation of the diode current so losses due to the reverse recovery are reduced as well.

\section{Design Challenges Of Interleaved Boost Converter}

The operation of two phase interleaved boost converter is explained which is shown in the figure 2 . Firstly when the device S1 is turned ON, the current in the inductor iL1 increases linearly. During this period energy is stored in the inductor L1. When S1 is turned OFF, diode D1 conducts and the stored energy in the inductor ramps down with a slope based on the difference between the input and output voltage. The inductor starts to discharge and transfer the current via the diode to the load. After a half switching cycle of S1, S2 is also turned ON completing the same cycle of events. Since both the power channels are combined at the output capacitor the effective ripple frequency is twice than that of a single-phase boost converter. The amplitude of the input current ripple is small. This advantage makes this topology very attractive for the renewable sources of energy. The gating pulses of the two devices are shifted by a phase difference of $360 / n$, where $n$ is the number of 
parallel boost converters connected in parallel. For a two-phase interleaved boost converter $n=2$, which is 180 degrees. By splitting the current into two power paths, conduction $\left(I^{2} R\right)$ losses can be reduced, increasing the overall efficiency compared to a single-phase converter. Because the two phases are combined at the output capacitor, effective ripple frequency is doubled that making ripple voltage reduction much easier. Likewise, the power pulses drawn from the input capacitor are staggered, reducing the ripple current requirements.

In the figure 2 it can be seen that the input current, I, for two phase interleaved boost converter is the sum of each channels inductors currents. As the two devices are phase shifted by 180 degrees, the input current ripple produced is the smallest.

An induction or asynchronous motor is a type of AC motor where power is supplied to the rotor by means of electromagnetic induction. The speed of the induction motor is controlled by the frequency of the supply voltage. When driven a fixed line frequency, the motor reduces the rotation speed. When used in this way, the induction motors are usually run so that in operation the shaft rotation speed is kept above the peak torque point.

$$
I_{\text {in }}=\frac{P_{\text {in }}}{V_{\text {in }}}
$$

Where $P_{\text {in }}$ is the input power and $V_{\text {in }}$ is the voltage.

$$
\begin{aligned}
\Delta I_{l 1, l 2} & =\frac{V_{i n} D}{f_{S W} L} \\
\mathrm{~L} & =\frac{V_{S} D}{\Delta i_{1 F}}(4)
\end{aligned}
$$

Where Vs represent the source voltage IL represent the inductor current and Fs Is the switching frequency

$$
\mathrm{C}=\frac{V_{o} D F}{R \Delta V_{O}}
$$

\section{Simulation Model}

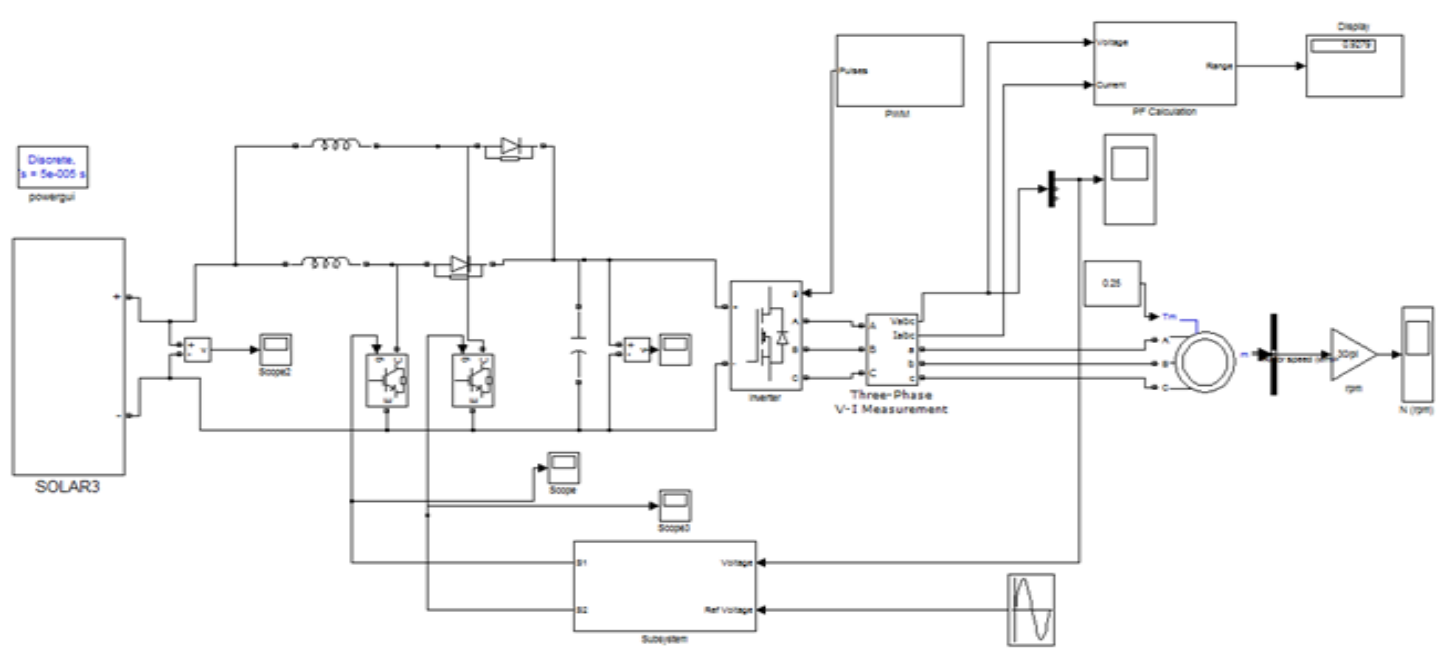

Fig3:Simulation model

Two Boost converters working on same switching frequency are connected in parallel supplied from the same rectified dc from ac supply mains and feeding a load. Two boost converters are connected in parallel with same control technique used as earlier in single boost PFC circuit switches working with same switching frequency and different duty cycles (phase shifting of switch conduction).As parallel connection is used, smoothening of line current will occur and because of PFC circuit line current harmonics will reduce. 


\section{RESULTS AND DISCUSSION}

Fig.4 shows the P-V curves obtained at the two temperatures. The circular markers in the graphs represent experimental $(\mathrm{V}, \mathrm{I})$ and $(\mathrm{V}, \mathrm{P})$ points extracted from the datasheet. Fig.4 proves that the model accurately matches with the experimental data both in the current and power curves as expected.

$\mathrm{X}$ axis-Time, $\mathrm{Y}$ axis-Voltage

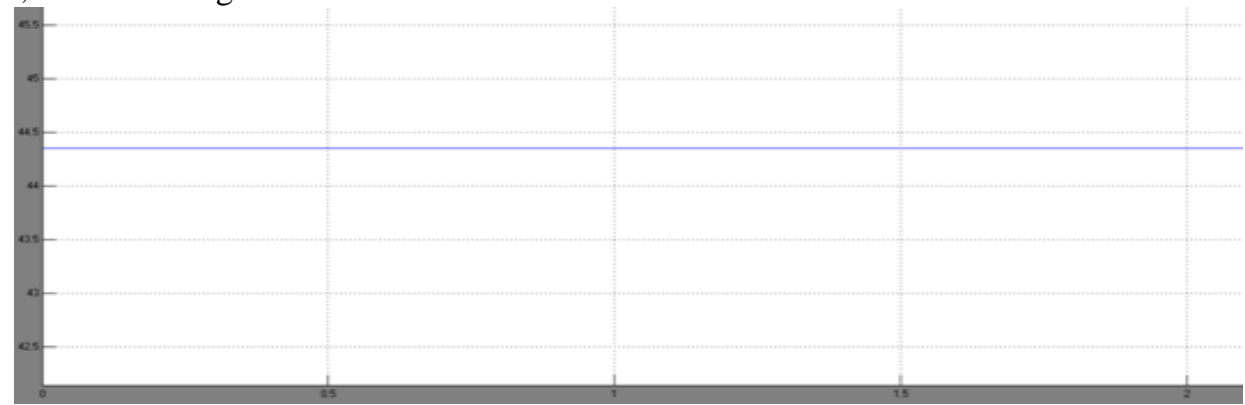

Fig 4: PV model output

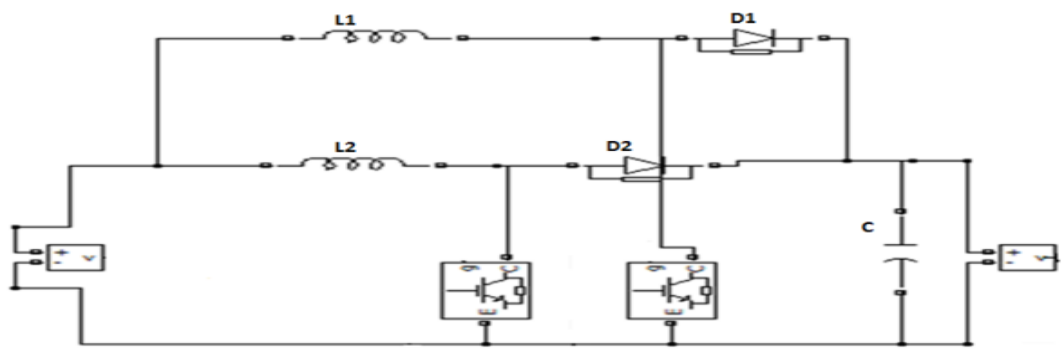

Fig 5: Interleaved Boost Converter diagram

$\mathrm{X}$ axis-Time

Y axis-Voltage

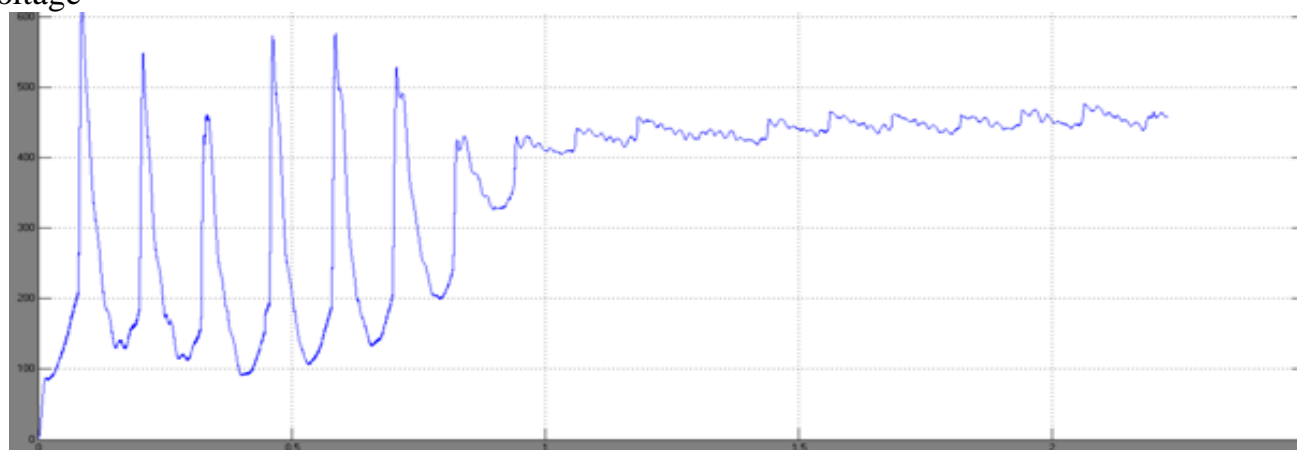

Fig 6: Interleaved boost converter output

This is the interleaved boost converter output. in This $\mathrm{x}$-axis shown the voltage and $\mathrm{y}$-axis shown the time at 450 voltage its constant. The following equations and the graph of Figure show how the ratio of outputcapacitor ripple current and the change in inductor current vary with duty cycle. Figure illustrates that the maximum inductor ripple current cancellation occurs at 50\% duty cycle.

$\mathrm{X}$ axis-Time

Y axis-Voltage

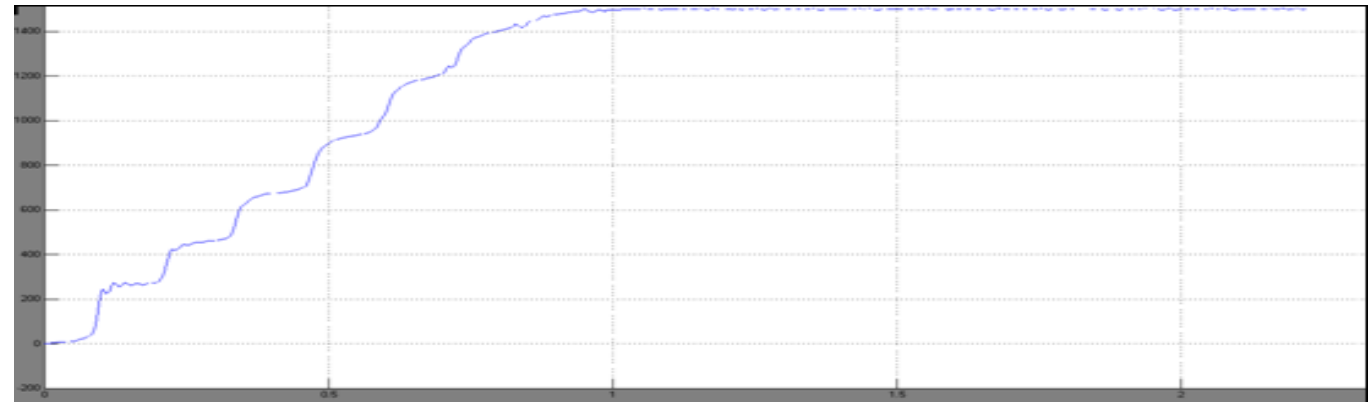

Fig 7: Induction motor output 
$\mathrm{X}$ axis-Time

Y axis-Voltage

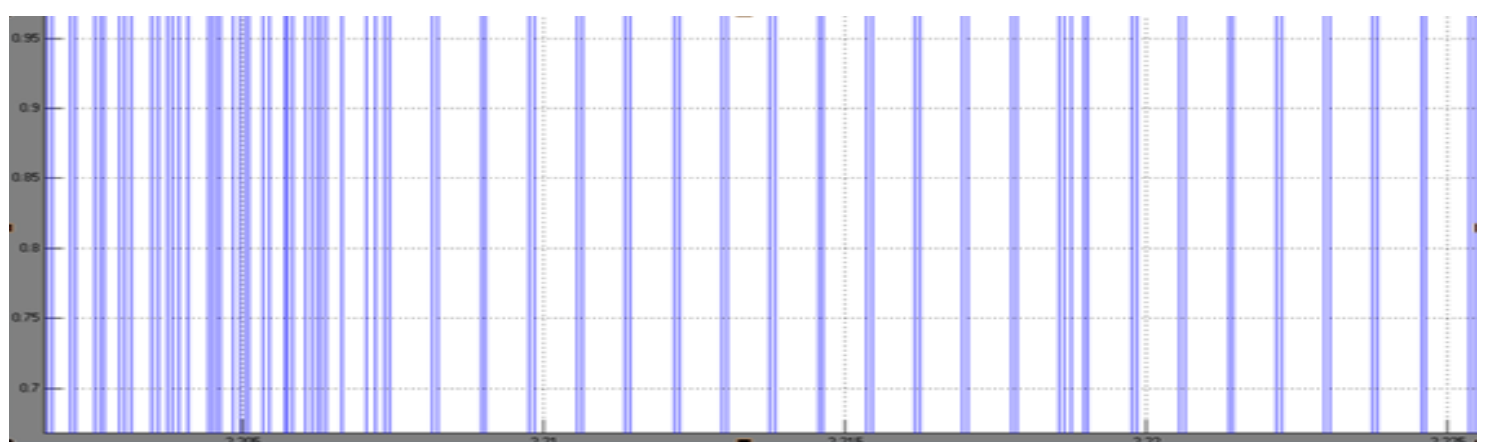

Fig.8: PWM output for IGBT2

This is the PWM output for interleaved boost converter switches. The process of PWM conversion is non-linear and it is generally supposed that low pass filter signal recovery is imperfect for PWM. The PWM sampling theorem shows the PWM conversion can be perfect. The theorem states that any band limited baseband signal within \pm 0.637 can be represented by a pulse width modulation (PWM) waveform with unit amplitude. The number of pulses in this waveform is equal to the number of Nyquist samples and the peak constraint is independent of whether the waveform is two-level or three-level.

\section{Conclusion}

In this paper, a new interleaved boost PFC converter is proposed, which provides switching for the power MOSFETs, through a circuit. This circuit provides reactive current during the transition times of the MOSFETs [13]-[17] to charge and discharge the output capacitors of the MOSFETs. In addition, the control system effectively optimizes the amount of reactive current required to achieve ZVS for the power MOSFETs. The frequency loop, which is introduced in the control system, determines the frequency of the modulator based on the load condition and the duty cycle of the converter. The experimental results and efficiency curves show the superior performance of the proposed converter compared to the conventional one. The power factor correction circuits were employed with PI controller to optimize the performance. So with this effect, the converter module performs very well with the power factor as high as 0.93 .

\section{Acknowledgement}

Authors would like to thank all the researchers who have contributed in this field of research. The comments of anonymous reviewers to improve the quality of this paper are also acknowledged.

\section{Reference}

[1] R. Giral, L. Martinez-Salamero, and S. Singer, "Interleaved convertersoperation based on CMC," IEEE Trans. Power Electron., vol. 14, no. 4,pp. 643-652, Jul. 1999.

H. Kosai, S. McNeal, B. Jordan, J. Scofield, B. Ray, and Z. Turgut,“Coupled inductor characterization for a high performance interleavedboost converter," IEEE Trans. Magn., vol. 45, no. 10, pp. 4812-4815,Oct. 2009.

[3] C. A. Gallo, F. L. Tofoli, and J. A. C. Pinto, "A passive lossless snubberapplied to the AC-DC interleaved boost converter," IEEE Trans. PowerElectron., vol. 25, no. 3, pp. 775-785, Mar. 2010.

[4] Y. Jang and M. M. Jovanovic, "Interleaved boost converter with intrinsicvoltage-doubler characteristic for universal-line PFC front end," IEEETrans. Power Electron., vol. 22, no. 4, pp. 1394-1401, Jul. 2007.

[5] F. Musavi, W. Eberle, and W. G. Dunford, "A high-performance single-phasebridgeless interleaved PFC converter for plug-in hybrid electricvehicle battery chargers," IEEE Trans. Ind. Appl., vol. 47, no. 4, pp. 1833-1843, Jul./Aug. 2011.

[6] C. A. Gallo, F. L. Tofoli, and J. A. C. Pinto, "Two-stage isolated switch modepower supply with high efficiency and high input power factor,"IEEE Trans. Ind. Electron., vol. 57, no. 11, pp. 3754-3766, Nov. 2010.

[7] M. O’Loughlin, "UCC28070 300-W interleaved PFC pre-regulator designreview," TI Appl. Rep. SLUA479B, Aug. 2008, revised Jul. 2010.

[8] C.-P. Ku, D. Chen, C.-S. Huang, and C.-Y. Liu, "A novel SFVM-M3control scheme for interleaved CCM/DCM boundary-mode boost converterin PFC applications," IEEE Trans. Power Electron., vol. 26, no. 8,pp. 2295-2303, Aug. 2011.2303, Aug. 2011.

[9] Y. T. Chen, S. M. Shiu, and R. H. Liang, "Analysis and design of a zero-voltage-switching and zero-current-switching interleaved boost converter,'IEEE Trans. Power Electron., vol. 27, no. 1, pp. 161-173, 2011.

[10] G. Yao, A. Chen, and X. He, "Soft switching circuit for interleaved boost converters," IEEE Trans. Power Electron., vol. 22, no. 1, pp. 80-86, Jan.2007.

[11] B.-R. Lin, H.-K. Chiang, C.-Y. Tung, and C.-Y. Cheng, "Implementation of an interleaved ZVS boost-type converter," in Proc. IEEE Int. Symp.Ind. Electron., Jul. 5-8, 2009, pp. 819-824.

[12] N. Jain, P. Jain, and G. Joos, "A zero voltage transition boost converter employinga soft switching auxiliary circuit with reduced conduction losses,"IEEE Trans. Power Electron., vol. 19, no. 1, pp. 130-139, Jan. 2004. 
[13] R. Streit and D. Tollik, "A high efficiency telecom rectifier using a novelsoft-switching boost-based input current shaper," in Proc.Conf. Rec. IEEEINTELEC, 1991, pp. 720-726.

[14] K. M. Smith and K. M. Smedley, "A comparison of voltage-mode softswitchingmethods for PWM converters," IEEE Trans. Power Electron.,vol. 12, no. 2, pp. 376-386, Mar. 1997.

[15] C.-J. Tseng and C.-L. Chen, "Novel ZVT-PWM converter with activesnubbers," IEEE Trans. Power Electron., vol. 13, no. 5, pp. 861-869,Sep. 1998.

[16] G. Moschopoulos, P. Jain, G. Joos, and Y.-F Liu, "Zero voltage switchedPWMboost converter with an energy feed forward auxiliary circuit," IEEETrans. Power Electron., vol. 14, no. 4, pp. 653-662, Jul. 1999.

[17] T.-W. Kim, H.-S. Kim, and H.-W. Ahn, “An improved ZVT PWM boostconverter," in Proc. Conf. Rec. IEEE Power Electron. Spec. Conf., 2000,pp. 615-619. 